\title{
A RETÓRICA COMO SUPORTE DA 'VERDADE' EM UM LIVRO DE HISTÓRIA DO SÉCULO X
}

\section{The rhetoric as support for 'truth' in a 10th century History book}

\author{
Bruno Casseb Pessoti (UFOB) ${ }^{1}$ \\ Docente da Universidade Federal do Oeste da Bahia - Departamento de História \\ ORCID: https://orcid.org/0000-0002-6905-0570 \\ E-mail: casseb.pessoti@ufob.edu.br
}

Recebido em: 28/06/2020

Aprovado em: 29/07/2020

\begin{abstract}
Resumo: Este artigo pretende discutir algumas das propostas narrativas utilizadas pelo monge Richer da Abadia de Saint-Remi na escrita de um livro de História no fim do século X e como elas foram empregadas para se chegar à 'verdade'. Os Historiarum Libri Quatuor foram escritos na última década antes do fim do milênio e seu autor testemunhou a mudança da dinastia carolíngia para a capetíngia, tendo sido o único a escrever sobre esses eventos ao tempo em que se desenrolavam historicamente. Além de fazer buscas em bibliotecas, Richer consultou e copiou documentos que ajudaram a embasar seus escritos. A obra do monge de Saint-Remi aparece como peça central para ajudar a dar inteligibilidade a esse período que antecede a passagem do primeiro milênio no Regnum Francorum. Depositário da tradição ciceroniana, Richer se utilizou de recursos narrativos como a plausibilidade e a verossimilhança e estabeleceu um interessante diálogo entre História e a Retórica. Destarte, sua proposta de escrita da História precisa ser contextualizada e associada às diretrizes que sustentavam sua filiação intelectual. Pretendemos refletir sobre as propostas de 'verdade' que Richer ofereceu aos seus leitores e ouvintes e as ferramentas intelectuais que ele utilizou para chegar até elas.
\end{abstract}

Palavras-chave: Plausibilidade; Verdade; Século X; monge Richer da Abadia de Saint-Remi

Abstract: This article aims to discuss some of narrative proposals used by Richer, monk at Saint-Remi Abbey, in a History book from the end of 10th century and how they were employed to reach the 'truth'. The Historiarum Libri Quatuor were written in the last decade before the millennium and its author witnessed the change from carolingian dinasty to capetingian having been the only one to write about these events to the time that they historically occured. In addition to search in libraries, Richer consulted and copied documents that helped to base his writings. The work of Saint-Remi's monk appears as a centerpiece to help to give intelligibility to the period that precedes the passage of the first millennium in the Regnum Francorum. Keeper of the Ciceronian tradition, Richer used narrative resources such as plausibility and verisimilitude and established an interesting dialogue between History and Rhetoric. Therefore, his proposal of History writing needs to be contextualized and associated with the guidelines that supported his intellectual affiliation. We intend to reflect on the 'truth' proposals that Richer offered to his readers and listeners and the intellectual tools he used to get to those.

Key-words: Plausibility; Truth; Tenth Century; monk Richer of the Abbey of Saint-Remi 
No ano de 972 d. C., o monge Richer (940-998) conheceu Gerbert d'Aurrilac (946-1003), exatos três anos depois de ter entrado para a Abadia de Saint-Remi, localizada em Reims, no nordeste do Reino dos Francos, na região de Champanhe. Gerbert era figura de proa no movimento de reforma pela qual passava a cristandade ocidental e que se desenvolveria pelos dois séculos subsequentes. Além de grande intelectual, ele estava envolvido em redes de grande influência política, prova disso seria sua indicação para ocupar a Sé Romana, no ano de 999. Após a sagração, seu pontificado duraria apenas quatro anos, mas os ideais reformadores seriam levados adiante e se intensificariam, principalmente, a partir da segunda metade do século XI. ${ }^{2}$

Foi Gerbert, ao tempo em que fazia parte da comunidade monástica de SaintRemi, quem incumbiu Richer de elaborar uma obra histórica. A produção escrita era um imperativo e fazia parte dos objetivos intelectuais aos quais se direcionava grupo de religiosos que tentava impor novos hábitos ao clero. A escrita da história das instituições religiosas deveria ser um mecanismo sobressalente a auxiliar os membros da Igreja a balizarem e conduzirem seus comportamentos com base nos exemplos do passado. A memória estaria, destarte, a serviço de uma conduta mais moralizante. Como afirmou Gabrielle Spiegel (1997, p. 84), "a vida na Idade Média era governada pelo costume, isto é, pelo precedente histórico, de tal forma que mesmo as inovações nas práticas sociais e jurídicas foram agraciadas com a força dos costumes."

A tarefa de trazer a lume uma trajetória histórica dos francos foi prontamente aceita e para além dos objetivos que podem ser atrelados às reformas então em curso, pode-se entrever uma plêiade de finalidades que despontam do argumento do autor:

Se me entrego, Santíssimo Padre Gerbert, ao trabalho de escrever sobre as guerras dos gauleses, é por respeito ao seu comando. A enorme utilidade de uma atividade como essa e a riqueza da matéria concernente ao tema são múltiplas, o que faz com que me renda à tarefa insuflado pelo ânimo (RICHERI, 1845, Prologus, p. 2). ${ }^{4}$

A obra de Richer foi dividida em quatro livros e tem sido designada como Histórias, Quatro Livros de História ou História da França pela literatura especializada. Depois de muito tempo esquecida, foi reediata por George-Henri Pertz (GAUDET, 1845, XXIII-XXIV) em meados da década de 30 do século XIX. Foi o próprio Pertz quem estabeleceu os critérios segundo os quais o monge de Saint-Remi teria escrito seu livro de histórias. A execução da obra teria se dado ao longo de três anos, 995-998. No primeiro ano, Richer escreveu o livro I e mais da metade do livro II. Nesse recorte do texto, as Histórias dão conta dos eventos transcorridos no Reino dos Francos de 888 até 948 . Nos dois anos subsequentes, o livro II foi finalizado e foram escritos os livros III e IV, que retraçam eventos ocorridos até 998. Há outras propostas de periodização que apresentam algumas variações. Michel Sot (1988, p. 725), por exemplo, afirma que as Histórias foram escritas entre 991 e 998.

A consulta e utilização das obras do monge Flodoard ${ }^{5}$ (894-966), também associado à Abadia de Saint-Remi, podem ser apresentadas como molas mestras para a elaboração dos primeiros livros das Histórias. Além das referências extraídas do trabalho de Flodoard, Richer contou com outros elementos que ajudaram a burilar sua formação intelectual e se manifestaram em sua narrativa. Ele nutria uma grande 
admiração por seu mentor e incentivador, Gerbert d'Aurillac, com quem estudou matemática, história, literatura e oratória. Ademais, se entregava à leitura dos clássicos latinos, manifestando especial apreço pela obra de Salústio (SOT, 1988, p. 725).

Jason Glenn afirma que Richer era versado nas artes liberais e que elas, não apenas, foram imprescindíveis para sua formação intelectual, como também deixaram traços nítidos em seus escritos. Segundo Glenn (2004, p. 57), "sua obra confirma um conhecimento, pelo menos, básico do quadrivium [...] mas, dada sua produção histórica e as demonstrações de habilidade retórica que ela apresenta, ele provavelmente dedicou mais tempo ao trivium". 6 ' 'historiador' confirma, ainda, sua condição de 'pesquisador' tendo feito viagens a Chartres para consultar manuscritos médicos presentes em seus arquivos. Ele também se dedicou à cópia de textos e documentos encontrados no arquivo da catedral - tais como correspondências de bispos e relatos de sínodos - que, certamente, forneceram-lhe preciosas informações sobre a história de Reims (GLENN, 2004, p. 58). Não apenas isso, o autor das Histórias teve acesso a inúmeras coleções de leis canônicas e seculares cujas leituras auxiliaram no aprimoramento de sua atuação como historiógrafo uma vez que esses textos tinham "propósitos que não eram meramente legislativos, mas também registros históricos do passado franco" (GLENN, 2004, p. 58). ${ }^{7}$

Para além desses elementos atinentes à formação intelectual de Richer, é preciso ter em conta que ele acompanhou pessoalmente os reinados de Lotário (954-986), Luis V (986-987) e a mudança da dinastia carolíngia para a capetíngia, ocorrida em 987. A ascensão de Hugo Capeto à condição de rei foi o desfecho de um processo que se desenrolou por um século e que teve no autor das Histórias a única 'testemunha ocular' a escrever sobre esses eventos contemporaneamente ao seu decorrer histórico. Isso fez com que seu trabalho fosse considerado como local privilegiado para pesquisas de fatos concernentes ao universo político do Reino dos Francos.

Imprescindível se faz mencionar a importância de ser testemunha coetânea dos acontecimentos para a credibilidade de quem escrevia obras históricas durante a Idade Média. Bernard Guenée (1980, p. 129-147) demonstrou a validade de que desfrutava uma narrativa histórica que repousava sobre a visão direta dos acontecimentos por parte de quem os descrevia. Testemunhar pessoalmente os eventos, narrar os episódios 'vistos' ou 'presenciados' atribuía ao relato um estatuto absolutamente diferenciado, dotado de uma confiabilidade lastreada pela experiência direta e imediata daquele que pretendia tornar conhecidas as ideias inerentes à sua narrativa (SEGUY; LUCKEN, 2000, p. 11). Como disse Elisabeth Lapina (2007, p. 117-139), a visão se coadunava, assim, como representação sensível das formas de apreender os acontecimentos da maneira mais íntima que se pudesse imaginar.

Ainda que outros autores tenham descrito o advento da dinastia capetíngia, os valores que permeavam a produção intelectual no alvorecer do segundo milênio concediam maior credibilidade aos relatos daqueles que estavam mais próximos dos eventos, de preferência que tivessem participado ou testemunhado pessoalmente o seu desenrolar. Isso conferiria um estatuto absolutamente ímpar às Histórias de Richer e uma validade sem concorrentes como a representação mais fidedigna dos eventos que o monge se propôs a narrar. "Quanto mais antiga é uma fonte, dizia-se, e melhor ela deve apreender um fato antigo. E pode-se atribuir a maior confiança aos textos contemporâneos dos fatos que eles relatam" (GUENÉE, 1980, p. 141). ${ }^{8}$ 
Mesmo com esse arsenal de atributos, o historiador Justin Lake, que nos últimos anos tem se dedicado a analisar a obra de Richer, afirmou que o trabalho do monge tende a inspirar pouca credibilidade e confiança entre os historiadores modernos. Lake (2009, p. 223) assevera que apesar da inquestionável contribuição das Histórias como fonte para a História Política e Eclesiástica do Reino dos Francos, seu autor tem sido considerado, já há tempos, como alguém "que, claramente, tem uma relação casual com a verdade". ${ }^{9}$ Destarte, as informações apresentadas por Richer despertam o interesse dos pesquisadores apenas na medida em que podem ser confirmadas como dignas de fé e depositárias de supostas ou possíveis verdades, ou seja, somente quando são referendadas por outras fontes.

Certamente, um dos elementos que contribuem para enfraquecer a credibilidade de que a obra de Richer tem desfrutado, advém do fato de que ele preencheu lacunas concernentes aos fatos que se dispôs a narrar inventando diálogos, discursos, descrições de batalhas, eventos, etc.. Para historiadores contemporâneos, a condenação destes procedimentos e o questionamento sobre a validade das informações advindas de um autor com esse comportamento parecem absolutamente naturais e aceitáveis. Mas, na verdade, não são. Essas críticas são feitas com base em critérios válidos em um contexto de produção do conhecimento histórico que está há mais de mil anos de distância da fonte e do autor em questão. A análise dessa obra exige, antes de qualquer coisa, o entendimento de que "o conceito de 'verdade' dos 'historiadores' medievais diferia do nosso" (GRANSDEN, 1992, p. 128). ${ }^{10}$ O que Bernard Guenée (198, p. 150) disse sobre os historiadores do século XII, também pode ser atribuído aos que escreveram obras históricas no século X: eles não carecem de espírito crítico, "simplesmente, sua crítica histórica repousava em princípios que não são mais os nossos". ${ }^{11}$

Richer utilizou recursos retóricos advindos das tradições clássicas que permearam e influenciaram a produção intelectual durante toda a Idade Média. Plausibilidade, clareza e brevidade são três das virtudes que uma narrativa deveria encerrar, de acordo com os manuais de retórica da antiguidade que sobreviveram e foram utilizados pelos homens letrados da Idade Média (LAKE, 2009, p. 225). Não apenas isso, o mentor intelectual de Richer, Gerbert d'Aurrilac, era um ciceroniano convicto e dedicado e um dos oradores mais habilidosos e reconhecidos do seu tempo. O autor das Histórias pretendeu, assim, mais do que assegurar a verdade absoluta dos fatos apresentados, trazer aos seus leitores informações atinentes à ideia de plausibilidade (LAKE, 2009, p. 225). Para ele, esse conceito - e não o de verdade - era o padrão através do qual a história deveria ser escrita e julgada.

Henriette van der Blom (2010, p. 116) afirma que a famosa passagem "'Quem ignora que a primeira lei da história é não ousar dizer algo que seja falso?" denota "uma visão moral-didática da história, que precisa de uma certa dose de plausibilidade histórica." 12 Verdade e plausibilidade representavam formas distintas utilizadas na escrita de textos históricos, segundo cânones da tradição clássica. Elas deveriam ser, impreterivelmente, colocadas em prática em etapas diferentes da confecção de uma obra. Assim, se abster de contar mentiras não implicaria, obrigatoriamente, que "todas as referências aos exemplos históricos precisam ser verdadeiras e abrangentes em todos os aspectos" (VAN DER BLOM, 2010, p. 116). ${ }^{13}$

A busca pela verdade exigia a apresentação dos fatos - reconhecidos e atestados que serviriam de base para todo o argumento e sua posterior análise, que deveria ser marcada por uma isenção a toda prova. $\mathrm{O}$ objetivo seria a produção de uma narrativa 
que não tomasse qualquer partido diante dos fatos apresentados. A plausibilidade tirava seus méritos da superestrutura retórica e os fatos deveriam ser apresentados de maneira a oferecer suporte aos argumentos que o autor pretendesse demonstrar. Desde que não tomasse partido na análise dos eventos, o historiador poderia - na verdade, deveria acrescentar ficções plausíveis ao seu discurso. O artífice dessa proposta intelectual foi o famoso Arpinata que, segundo van der Blom (2010, p. 117), "apresentou a história como um assunto flexível no qual as interpretações podem variar para dar origem versões específicas, desde que a representação seja verossímil e convincente." 14

No livro II da obra De Oratore, de Cícero, há uma passagem em que Antônio pergunta a Cátulo: "não concorda que a escrita da história cabe a um grande orador e a um homem de grande mérito?". ${ }^{15}$ Ao que Cátulo responde: "se você se refere à escrita da história na forma como faziam os gregos, cabe ao mais sublime espírito; se à nossa maneira, não é necessário um orador, basta que não seja um mentiroso."16 Antônio redarguiu dizendo que mesmo entre os gregos, em seu começo, a história se apresentava em um estilo deveras medíocre. Entre os romanos, no princípio, a escrita da história "não era mais do que a confecção de anais" ${ }^{17}$ e tal proposta teve muitos seguidores que "imitaram essa forma de escrever, sem nenhum adorno, apenas para conservar os registros concernentes aos tempos, aos homens, aos lugares, aos acontecimentos"18 (CICERONIS, 1840, p. 211-212).

Assim, embelezar a narrativa com argumentos retóricos deveria ser parte constitutiva da tarefa intelectual de um historiador que se balizasse pelos preceitos da retórica ciceroniana. $O$ intuito não era falseá-la ou utilizá-la apenas para atingir determinados objetivos políticos e sim engrandecê-la enquanto produção intelectual e artística. Os anais se configuravam como exemplo do que não deveria ser feito em decorrência de sua monotonia e falta de ornamentos. Ao seguir essas premissas, Richer acreditava estar aprimorando o estilo da obra de Flodoard quando acrescentava argumentos plausíveis às informações colhidas dos Annales. Antes de qualquer coisa, a análise da ideia de plausibilidade deve trazer a percepção de que as ferramentas e os mecanismos intelectuais utilizados por Richer para escrever suas Histórias precisam ser contextualizados. Diante disso, considerar falaciosos ou invencionices os relatos históricos da obra do monge Richer de Saint-Remi significa não compreender o âmago dos seus objetivos intelectuais e de sua produção escrita.

$\mathrm{O}$ argumento retórico elaborado nas Histórias, certamente se revestiu de um enredo para se materializar e cumprir o papel que seu autor idealizou para ele. Ainda que pautado em eventos que não tenham de fato ocorrido da forma em que foram narrados, o discurso foi construído em bases que, para serem aceitas e validadas por seus contemporâneos - o que geralmente era o objetivo central das narrativas históricas medievais -, precisaria se basear em elementos narrativos passíveis de representar os fatos que se propunha a descrever. A história contada deveria ser 'aceitável' e se conectar com os sistemas de valores que determinavam o 'historicamente possível'.

O esforço intelectual do autor seria coroado de êxito se ele conseguisse convencer seus leitores e ouvintes do que havia escrito. Destarte, ele deveria ser capaz de ler e interpretar a realidade histórica para alcançar esse objetivo da forma mais cabal possível. $\mathrm{O}$ acréscimo de dados ficcionais não diminuía a seriedade ou teor histórico da narrativa e ainda lhe conferia um cariz literário que transitava entre diferentes estilos.

Essa necessidade de validação do discurso pelos contemporâneos ajuda a revelar traços das mentalidades dos grupos envolvidos no jogo de apropriação e legitimação 
dos elementos narrativos que se propunham a criar representações sobre o passado e mesmo sobre o presente. Além disso, desnudam-se as ações e comportamentos passíveis de serem atribuídos aos membros de diferentes grupos da hierarquia social e apresentam-se diante do pesquisador as representações que a sociedade elaborava de si mesma. A proposta discursiva de Richer se apresenta, destarte, como uma produção intelectual em que diferentes modalidades literárias podem ser encontradas, o que torna difícil uma definição sobre o estilo passível de enquadrá-la de forma categórica.

O historiador André Luis Miatello ao analisar a produção historiográfica medieval diz que

\footnotetext{
a historiografia pertencia mais ao âmbito das belas letras do que da verificação empírica, o que nos leva a constatar que obras históricas que se propunham fidedignas foram descaradamente falseadas em prol de um desejo de exaltação, legitimidade e reconhecimento, sem que deixassem de ser admitidas por verdadeiras, uma vez que correspondiam aos critérios do gênero histórico (TEIXEIRA e BASSI, 2015, p. 119).
}

A despeito de sua veneração pela tradição e da utilização que dava ao passado na busca pela legitimação de seus costumes e valores, a sociedade medieval estava "ativamente engajada em produzir essa tradição a partir de um processo complexo de transmissão, supressão e recriação" (GEARY, 199, p. 8). ${ }^{19}$ Isso fez com que a História fosse escrita a partir de eixos orientadores bastante distintos - até mesmo antagônicos e se direcionasse a uma ampla gama de objetivos. Ainda assim, esse falseamento 'descarado' da realidade pode soar como um argumento que vê na escrita da História exclusivamente seus elementos políticos e os interesses inerentes aos grupos associados aos produtores das obras que tinham a narrativa histórica como tema. Corre-se o risco de desconsiderar o conjunto de critérios que os letrados precisavam seguir - nos diferentes contextos que marcaram as trajetórias das sociedades medievais com suas características espaço-temporais - para que seus discursos fossem aceitos e referendados socialmente.

Além disso, fica obnubliada a ideia de que algumas idiossincrasias que escapam ao universo político podem ser reveladas a partir da análise dos valores que legitimavam os argumentos presentes nas obras históricas e que se entrechocavam na batalha das ideias - geralmente marcada por rituais de apropriações e ressignificações que se influenciavam reciprocamente. Por fim, mesmo as narrativas históricas deliberadamente falseadas e que buscavam legitimidade oferecem elementos que ajudam no entendimento de diferentes traços dos contextos em que foram escritas.

Não pretendemos negar a filiação de Richer a uma tradição política, nem defender a ideia de que os eventos narrados em seu livro estivessem alijados de posturas intelectuais capazes de revelar objetivos atinentes ao xadrez político de finais do século $\mathrm{X}$. Sugerimos, contudo, que esse não seja o único fulcro da análise de sua obra. $\mathrm{O}$ próprio Richer dá algumas sugestões sobre elementos que podem ser encontrados em seus escritos passíveis de extrapolar as informações atinentes aos objetivos políticos, sem necessariamente negá-los. O monge afirma que pretende trazer a lume "os costumes dos habitantes da Gália" (RICHERI, 1845, Lib. I, p. 8-10). A partir daí, segue uma descrição na qual alguns dos 'costumes' são apresentados: 
Os habitantes da Gália manifestam uma audácia inata e se mostram intolerantes às injúrias. Se forem provocados, atiram-se ao assalto furioso e atacam sem piedade. Quando são persuadidos com argumentos e convencidos, dificilmente têm o costume de refutar-se. Por isso, Jerônimo disse: 'a Gália não gera monstros sozinha, mas sempre foi iluminada por homens prudentes e eloquentíssimos.' (RICHERI, 1845 , Lib. I, p. 8-10). ${ }^{20}$

Rafael Bassi (2014, p. 71) enxergou nessa passagem "juízos de valor expostos pelo historiador acerca da sociedade sobre a qual está escrevendo." Não apenas isso, Bassi (2014, p. 72) afirma que Richer demonstra o desejo de representar os habitantes da Gália a partir de suas "características tanto boas quanto más." O que nos parece, é que Richer elabora uma representação dos francos que enaltece diferentes aspectos de sua personalidade e dos seus modos de agir. A uma beligerância incontrolável, por ser inata, se associa uma abertura para a ponderação lastreada pela possibilidade de convencimento a partir do uso de argumentos. Os bravos são também ponderados quando a ocasião exige e a razão atua. As noções de "características boas ou más" tiveram no século $\mathrm{X}$ valores distintos daqueles do século XXI e não podemos imputá-las a um universo contextual para o qual elas não apresentavam os sentidos conferidos pelas sociedades contemporâneas. O monge de Saint-Remi descreveu os francos como depositários de traços complementares que emergiam na medida em que cada situação exigia. A depender do desafio que se apresentava, a réplica variaria e poderia assumir cores físicas ou morais. Assim, segundo a ocasião, eles podiam lançar mão da 'audácia inata' ou dos 'comportamentos prudentes e eloquentíssimos' sem que houvesse uma mensuração de hierarquia entre as duas formas de agir.

Os vestígios da ancestralidade germânica que os intelectuais medievais se esforçaram por apagar desde o processo de conversão de Clóvis, no século VI, surgem na obra de Richer como partícipes das características inapeláveis dos francos sem que isso assuma qualquer tonalidade pejorativa. Estamos diante de uma representação que mescla valores e hábitos que ajudaram a formar a cultura do povo franco: ligados ao seu passado germânico, eles se fixaram na Gália e passaram por um processo de cristianização que ajudou a transformá-los, mas não anulou idiossincrasias que os definiam enquanto grupo. $\mathrm{O}$ aspecto cultural parece-nos um elemento imprescindível a ser considerado na análise da narrativa das Histórias. Os acréscimos plausíveis de que Richer se utiliza para adornar sua obra e associá-la à tradição da retórica ciceroniana não impedem que seja possível extrair do seu texto traços que ajudem a dar inteligibilidade ao século $\mathrm{X}$.

Vamos analisar, agora, um trecho da obra em que eventos políticos podem ser debatidos, bem como os possíveis posicionamentos de Richer diante das perspectivas que o contexto apresentava. Eles fazem parte da proposta narrativa do monge e podem ser identificados em diversos momentos da sua produção intelectual. Aqui, também, a plausibilidade se faz presente na descrição dos fatos narrados. No capítulo XXXVII do Livro II, Richer descreve a morte de Herbert II, Conde de Vermandois, acontecida no ano de 943. Herbert era um dos nobres mais influentes de todo o reino. Além de possuir inúmeras propriedades, ele era genro de Roberto I - filho de Roberto, o forte - e foi um dos principais artífices para a chegada dos capetíngios ao poder. A morte de Herbert já havia sido registrada nos Annales de Flodoard. Diante dos eventos apresentados sobre o ano de 943, Flodoard descreveu a morte do conde nos seguintes termos "Morreu o conde Herbert, seus filhos o enterraram em Saint-Quentin" (FLODOARD, 1905, p. 
87). ${ }^{21}$ As informações que Richer trouxe sobre a morte de Herbert foram um pouco mais detalhadas. Disse ele:

\begin{abstract}
Nesse ínterim, Herbert articulava inúmeros complôs maliciosos em que não perdia do horizonte o desejo de sacrificar novas vítimas para satisfazer suas ambições. Ele confraternizava com seus aliados vestido de forma suntuosa e, com a mão em riste, pronunciava solenemente um discurso quando foi acometido por uma apoplexia fulminante decorrente da abundância de humores. Seus dedos se fecharam, seus nervos se contraíram, sua boca entortou até a altura da orelha e ele morreu subitamente cercado por seus familiares que foram tomados pelo horror e pelo medo. Eles o levaram e enterraram em Saint-Quentin. Logo depois do seu sepultamento, seus filhos compareceram diante do rei que os recebeu com benevolência e esqueceu todos os erros cometidos por seu pai (RICHERI, 1845, Lib. II, p. 180). ${ }^{22}$
\end{abstract}

A descrição da morte do conde por Richer extrapola o relato sucinto oferecido pelos Annales de Flodoard. Existem outras versões sobre o decesso de Herbert II: Raul Glaber atribui sua morte a uma doença terrível e outra tradição diz que ele foi enforcado por ordem do rei Luis IV (RICHER, 1930, p. 186-187). Robert Latouche (RICHER, 1930, p. 187) afirma que a versão apresentada por Richer é uma invenção. É possível entrever, nessa passagem, elementos da narrativa histórica richeriana que tiveram os preceitos estruturais da retórica de Cícero como base.

Pouco antes de morrer, o conde é apresentado em trajes suntuosos, com o dedo erguido em um discurso solene direcionado aos seus apoiadores. Nessa postura que denota toda a soberba do seu comportamento, Herbert foi fulminado por uma crise que fez com que sua boca se retorcesse até a orelha e que suas mãos e nervos se contraíssem antes que ele caísse morto em uma cena chocante para os que a presenciaram. Herbert foi representado como ardiloso e em vias de preparar estratagemas para arruinar pessoas e alimentar suas ambições. Diante de alguém com esses comportamentos, a morte na narrativa se revestiu de aspectos exemplares e moralizantes. O desfecho foi condizente com as atitudes atribuídas ao conde pela representação elaborada por Richer.

Em contraste com os ardis de Herbert, o rei - Luis IV - se apresenta benevolente e perdoa os erros cometidos por ele. Quando se imagina que Carlos III, pai de Luis IV, foi capturado por Herbert e mantido no cativeiro até a morte (informação que as Histórias trazem nos capítulos XLVI-XLVII do Livro I, RICHERI, 1845, Lib. I, p. 8793), a magnanimidade do rei por perdoar o conde de Vermandois e receber seus herdeiros com afabilidade fica ainda mais evidenciada. Nesse caso, há uma associação inescapável entre o comportamento moral e a condução dos assuntos políticos. O rei aparece como depositário de traços como benevolência e equilíbrio, características indispensáveis para um bom governante.

A morte de Herbert nos moldes em que ela aconteceu se configurou como uma punição pela sua maneira equivocada de se dedicar às atividades políticas. Diante do poder de que dispunha o conde e das responsabilidades que deveria ter assumido - dada a posição que ele ocupava na hierarquia da sociedade - sua conduta moral era absolutamente inaceitável. Além do claro apoio dado ao monarca, o que por si só já denota uma postura política assumida nas Histórias, a narrativa richeriana evidencia a 
condenação moral de uma liderança política que não apresentava comportamento condizente com seu estatuto de autoridade pública.

Como apontou Chris Wickham (2019, p. 579), algumas das tradições intelectuais e políticas que podem ser associadas ao século IX, não haviam desaparecido no século seguinte. Mas, não podemos deixar de considerar que, certamente, elas passaram por transformações. Rosamond Mckitterick (1995, p. 36) afirma que os carolíngios "se revelaram profundamente comprometidos com a palavra escrita para comunicação, administração e registro." ${ }^{, 3} \mathrm{O}$ uso da escrita nos moldes elaborados pela dinastia carolíngia deu origem a um universo intelectual que se atrelava a inúmeros objetivos e se destinava a uma infinidade de funções. Mckitterick (1995, p. 36) enfatiza o papel das capitulares e diz que elas eram parte de um processo de padronização que buscava consolidar a autoridade e unir um reino marcado pela disparidade. Esses documentos eram utilizados pelos magnatas para "divulgar medidas de legislação e administração, exortação, relatos sobre política e fervor moral." 24

Esse universo cultural gestado no mundo carolíngio engloba a elaboração de uma plêiade de trabalhos que se associavam às mais diferentes formas, propostas, objetivos, estilos, origens, funções. A admoestação ao comportamento dos soberanos era prática comum no século IX através de exortações nas quais política e moral se imiscuíam e se manifestavam em diferentes propostas veiculadas pela produção intelectual. Os monarcas depositários de uma autoridade concedida e legitimada pela divindade e incumbidos dos deveres da administração dos assuntos políticos deveriam ser portadores de uma conduta que servisse de exemplo a todos os súditos. Quando isso não acontecia, abria-se a possibilidade de reprimenda decorrente das ações consideradas moralmente inadequadas. A disseminação da ideia de que a moral deveria ser fervorosamente perquirida atingiu seu paroxismo no século IX e ofereceu a possibilidade para que mesmo intelectuais de menor envergadura e prestígio pudessem "repreender os reis em seus deveres morais" (WICKHAM, 2019, p. 579).

$\mathrm{O}$ século $\mathrm{X}$ se marcou por um processo de fragmentação e regionalização que, no Regnum Francorum, os últimos carolíngios não conseguiriam reverter. A condenação moral do soberano, trivial no século IX, se direcionou, na centúria seguinte, aos potentados que se multiplicaram, sobretudo, na parte ocidental da Francia. Assim, uma reprimenda moral que no século IX poderia ser feita a um rei - ou mesmo ao imperador - no século $\mathrm{X}$ passou a ser encaminhada também àqueles que ocupavam o topo da hierarquia nos potentados regionais e locais que apresentassem comportamentos inadequados. O caráter regional da autoridade fez com que os destinatários das advertências passassem a ser também as lideranças aristocráticas em seus enclaves de poder. Os magnatas poderiam ser recriminados, criticados, admoestados de que sua conduta moral não se mostrava condizente com a responsabilidade política que estava sob sua alçada. As críticas, mesmo que assumissem uma tonalidade moral, não deixariam de incidir sobre o comportamento político dos grandes que precisassem de admoestação. Afinal de contas, a moral estaria umbilicalmente atrelada ao comportamento político de um indivíduo já que este era uma vitrine na qual aquela poderia ser vista e julgada.

Ainda que o desenvolvimento intelectual do mundo carolíngio tenha seguido rumos diferentes no século $\mathrm{X}$, é possível perceber resquícios da reforma moral que intervinha na alta política nos moldes em que havia sido desenvolvida no século anterior. Durante o século IX, o rei era o destino mais importante das advertências 
morais que poderiam ser feitas mesmo por intelectuais de menor envergadura. À medida que sua autoridade se enfraquecia e passava a ser compartilhada com os nobres, a responsabilidade de manter uma linha de conduta moral atrelada às ações públicas se associava às obrigações dos aristocratas de forma mais efetiva. Quando essa conduta não era observada, os grandes se expunham às exortações, críticas e admoestações que deveriam ser encaminhadas a todos que assumissem as responsabilidades da condução da sociedade cristã.

A obra de Richer se configura como uma manifestação cultural dessa transformação política. Esta se anuncia nas páginas das Histórias através dos argumentos plausíveis de que seu autor se utilizou. É o que podemos inferir da representação oferecida por ele da morte do conde Herbert II, de Vermandois. O conde morreu em 943 e esse evento se conformou como substrato factual que recebeu os acréscimos plausíveis por parte do historiador ciceroniano. Os eventos que Richer criou - insuflado pelas diretrizes da retórica - trazem informações valiosas sobre o século X, já que a plausibilidade se ancora inevitavelmente no contexto. A descrição dos detalhes que antecederam à morte evidencia a utilização de argumentos que se tornam plausíveis quando se considera uma narrativa histórica elaborada nas últimas décadas antes do fim do primeiro milênio no Regnum Francorum: tanto os argumentos atinentes às manifestações físicas da crise de apoplexia, quanto os que atribuem o decesso do conde a atitudes moralmente condenáveis.

$\mathrm{O}$ autor das Histórias considerava Herbert indigno da autoridade que exercia e sua conduta moral justificava as críticas e admoestações que a narrativa imputou a seus atos. A condição de conde, os lastros familiares, as terras e a influência de que dispunha, a autoridade que suas redes de aliados e dependentes legitimavam, exigiam outra postura por parte dele. Por isso, há no texto uma relação de causa e efeito entre seu comportamento e sua morte na forma em que ela aconteceu. Sua atenção para com os assuntos públicos e seus modos de agir não eram condizentes com a sua força política, nem com suas possibilidades de ação prática. Destarte, ele se apresentava como alvo em potencial para críticas como as que foram elaboradas por Richer.

Muito mais do que defensor das dinastias que disputavam a hegemonia no Reino dos Francos, Richer pode ser visto como manifestação intelectual dos pilares culturais que os carolíngios haviam desenvolvido nos últimos 200 anos, em uma digressão que só se torna possível recorrendo-se à 'longa duração' (BRAUDEL, 1992, p. 41-78). A relação entre essa tradição intelectual e a política coordenada pela aristocracia alto medieval era absolutamente nevrálgica. Uma das finalidades precípuas era a criação de um sistema de governo eficaz e moralmente estruturado que fosse capaz de garantir a paz nesse mundo e pela eternidade. A obra de Richer se conforma, assim, como herdeira cultural de uma manifestação política que começou a ser cunhada pela civilização carolíngia pouco depois de sua chegada ao poder. Os acréscimos plausíveis que ele cria ao descrever a morte do conde Herbert II se legitimam e se explicam pelo diálogo entre as permanências da tradição clássica e as heranças político-intelectuais dos séculos VIII e IX nos moldes em que elas se apresentavam no final do século $\mathrm{X}$.

Tomemos um segundo exemplo extraído das Histórias. No capítulo LIX do Livro II, Richer traz a notícia da morte de Derold, bispo de Amiens, acontecida no ano de 946. Essa informação pode ter sido extraída dos Annales, de Flodoard. Ao descrever os eventos que tiverem lugar em 946, Flodoard (1905, p. 103) menciona a morte de Derold da seguinte maneira: "Morreu Derold, bispo de Amiens." ${ }^{25}$ Mais lacônico, impossível. 
Interessante perceber que Flodoard oferece muitas informações referentes ao ano de 946. Foi um ano particularmente intenso no xadrez político do Reino dos Francos e isso salta aos olhos quando se lê os Annales.

Mas, no que tange ao bispo de Amiens, que por ora nos interessa, ele apenas menciona ter sido esse o ano da sua morte. Richer trouxe informações concernentes a alguns eventos protagonizados por Derold que extrapolam o que poderia ter sido colhido a partir da leitura de Flodoard. Robert Latouche asseverou que a autenticidade das informações apresentadas nessa passagem das Histórias é duvidosa (RICHER, 1930, p. 224-225). O próprio Latouche as designa como "anecdote plaisante", uma piada agradável (RICHER, 1930, p. 225). Como Richer fez pesquisas e teve acesso a documentos médicos, não seria impossível que ele tivesse chegado às informações e aos detalhes atribuídos por ele à trajetória de Derold. Por outro lado, dada sua filiação intelectual ciceroniana e os preceitos de verossimilhança que reconhecidamente utilizou em sua obra, é possível que estejamos diante de acréscimos plausíveis. Fica a encargo do leitor a escolha por qualquer uma das possibilidades. ${ }^{26}$ Segue abaixo o trecho em que Richer apresenta Derold, o bispo de Amiens, em um episódio específico de sua vida:

\section{LIX - Como Derold foi enganado por um médico e depois o enganou.}

Nesse tempo, morreu Derold, bispo de Amiens, distinto membro da corte e bastante próximo do rei. Ele era grande especialista na arte médica e, diz-se, que ao tempo em que servia ao rei no palácio, foi engando por um médico de Salerno e o enganou também em revide. Como ambos eram especialistas na arte médica, o rei acreditava que Derold fosse mais sábio e a rainha pensava ser o Salernitano e para resolver a questão, o rei encontrou uma maneira de averiguar quem sabia mais sobre os assuntos da natureza. $\mathrm{O}$ rei ordenou que ambos se juntassem a ele, como convidados, em sua mesa, dissimulando a real causa do convite, e nessas ocasiões fazia perguntas frequentes aos dois. Cada qual deveria responder às perguntas como pudesse. Derold, de sua parte, como havia sido educado nas artes liberais, oferecia respostas verossímeis, enquanto o médico de Salerno, ainda que não dispusesse de uma formação erudita, respondia com base na experiência amealhada por sua inteligência inata. Assim, por ordem do rei, eles vinham todos os dias e se sentavam lado a lado na mesa real. Certo dia houve um debate sobre as capacidades apresentadas por diferentes tipos de medicamentos e uma longa discussão sobre a eficácia da farmacêutica, da cirurgia e da botânica. $O$ Salernitano, como não dominava essas palavras estrangeiras, guardava um silêncio constrangido, por não poder oferecer explicações sobre elas. Movido por uma grande inveja, resolveu preparar a morte de Derold por uma substância venenosa ao tempo em que dissimulava, de forma maledicente, nutrir por ele uma grande afeição. Ele preparou o veneno e como estavam sentados juntos à mesa do almoço, o Salernitano jogou uma dose letal da poção que estava escondida em seu dedo do meio no molho de pimenta de que ambos se serviam na refeição. Derold se serviu do molho sem desconfiar e o veneno se espalhou rapidamente por seu corpo e fez com que se sentisse fraco. Levado pelos seus companheiros, ele anulou a força do veneno pela teriaca e depois de três dias voltou a se apresentar ao Salernitano, como de costume. Interrogado sobre o que havia acontecido com ele, respondeu que tinha sido acometido por uma febre leve e dissimulou que pudesse desconfiar do que havia de fato se passado. Seu adversário não suspeitou de nada. Quando voltaram a partilhar a mesa, Derold jogou o veneno que escondia entre o dedo mindinho e o indicador na comida que o Salernitano estava prestes a comer. $\mathrm{O}$ veneno se espalhou rapidamente pelas veias e destruiu o calor vital. Em grande agonia ele foi levado por seus companheiros que 
tentaram, em vão, reverter os efeitos do veneno. Então, ele exaltou Derold, o elevou à condição de mestre maior em medicina e, de forma veemente, solicitou que viesse em seu socorro. Derold, seguindo as ordens dadas pelo rei, ministrou o antídoto para o veneno, mas tomou os cuidados para não eliminá-lo completamente. Então, ao tomar a teriaca, toda a força do veneno se concentrou no seu pé esquerdo. Isso se deu de tal forma que o veneno ressurgiu, pelo que se conta, enquanto cuidava de seus negócios juntamente com seus familiares, por uma veia sob a forma de um grão de bico e foi empurrado de volta para o pé, ao entrar em contato com o antídoto. O longo embate entre esses dois agentes teve como consequência o aparecimento de buracos na superfície da pele do pé. Este se infeccionou e precisou ser dolorosamente amputado pelos cirurgiões (RICHERI, 1845, Lib. II, p. 214216). ${ }^{27}$

Diante de tudo que essa passagem nos oferece, fica a certeza de que a morte de Derold não é a única informação passível de análise. Há outros elementos que podem ser explorados a partir da descrição feita por Richer desses eventos que envolveram a participação do bispo de Amiens. Antes de qualquer coisa, Richer mostra o que parecem ser critérios de Luís IV (936-954) para a escolha de um membro da corte. A ideia de que as duas possibilidades em questão se apresentavam ao monarca advém da informação de que o casal real discordava quanto a quem seria o mais sábio entre Derold e o médico de Salerno. Ao deparar-se com a dúvida, o rei lança mão de um subterfúgio para averiguar quem era, de fato, o mais sábio - e, consequentemente, a melhor opção para ter como aliado: ele convida os dois para sua mesa, sem razão aparente, e coloca questões para ambos. Ao cabo de alguns encontros, Derold se mostra capaz de responder a questões que o médico de Salerno não consegue. A superioridade de Derold incomodou seu rival que preparou um ardil para matá-lo colocando veneno na sua comida. Envenenado, Derold não apenas conseguiu reverter o efeito do veneno como também ludibriou o médico de Salerno aparentando não desconfiar do que de fato the havia feito mal. Depois disso, ele preparou o revide e procedeu da mesma forma: envenenou o Salernitano. Novamente a superioridade de Derold ficou comprovada quando seu rival solicitou a ele que cuidasse dos males causados pelo veneno que fora colocado secretamente em sua comida. Os cuidados foram ministrados e o médico de Salerno foi salvo, mas terminou com o pé amputado. Interessante notar que o tratamento dado ao médico por Derold se seguiu a uma ordem do rei.

Vamos tomar alguns pontos para consideração. O médico de Salerno desfruta de uma autoridade inquestionável - atrelada ao local de onde vem, exarada na forma como Richer o nomeia - ainda que não tenha seu nome mencionado. Mesmo assim, seu despeito o levou ao desentendimento com Derold, em decorrência da preeminência intelectual deste. Essa superioridade se comprovou no desenrolar dos eventos que antecederam e naqueles que se seguiram ao envenenamento recíproco. $O$ mais importante parece ser o papel do rei em toda a trama. Antes do mais, mesmo preferindo Derold, o rei submete os dois médicos aos mesmos subterfúgios para saber quem era o mais sábio. Sabemos de antemão que Derold foi o escolhido pelas menções que Richer faz a ele como bispo e membro da corte. Mas a narrativa richeriana mostra que a discordância de alguém digno de confiança no seio da corte - a rainha - levou o rei a estabelecer critérios para a confirmação sobre quem seria o médico mais sábio.

Essa passagem oferece uma representação do rei como alguém que a despeito de suas próprias preferências, ouve a opinião de outros membros da corte. Ainda assim, é 
ele quem cria os critérios para a escolha do melhor caminho, do que seria mais prudente fazer, de como escolher pelo mais sábio e, por isso, mais digno de confiança. Mesmo sendo superior ao seu adversário nas ocasiões que se apresentaram a ele - tanto do ponto de vista intelectual como na ação prática, de confronto direto pela vida e morte Derold precisou atender a uma determinação do rei e teve que agir para salvar a vida de quem tentou tirar a sua. Destarte, o rei surge como alguém que não apenas dispõe do discernimento para tomar as decisões mais acertadas e seguir o melhor caminho trazendo os mais sábios para junto de si - mas também deixa claro que, a despeito da superioridade que seus aliados apresentem frente aos rivais, eles devem agir segundo ordens que emanem do monarca. A partir dos comandos dados pelo rei aos seus seguidores, os rivais podem ser salvos de condutas inadequadas ou equivocadas, mas há sempre consequências, aqui representadas pela amputação do pé do médico de Salerno.

Os aliados do rei são contemplados com benesses e Derold não fugiu à regra tendo sido elevado à condição de bispo de Amiens. A história reproduzida acima foi lembrada quando Richer mencionou o ano da morte de Derold. A alusão ao seu falecimento trouxe à obra richeriana o conjunto de elementos levados em conta para a escolha pelo rei de alguém que compôs sua corte e assumiu cargos importantes. É preciso ter em conta, ainda, a necessidade de que os registros concernentes ao passado apresentassem alguma utilidade pública, como defendia o próprio Cícero. Assim, além de legitimar as ações perpetradas pelo rei, esse episódio se reveste de certa utilidade pública ao sugerir o critério adotado pelo monarca para se ocupar das atribuições inerentes à sua condição e evidenciar que seu comportamento político envolvia o estabelecimento de parâmetros para escolher os mais aptos e incorporá-los aos cargos importantes do seu governo.

Quando refletimos sobre os desdobramentos que a narrativa de Richer trouxe às informações concisas oferecidas por Flodoard sobre Derold, ao invés de considerá-la indigna de confiança ou inescrupulosa, seria melhor olhar mais uma vez para as diretrizes ciceronianas de escrita da História. O Arpinata defendia que a história seria digna do nome apenas se fosse ornada. Se esse foi o caso e Richer criou ornamentos a partir do que pôde colher nos Annales de Flodoard, ele não fez nada além de seguir mais uma orientação do mestre da retórica que lhe influenciava sobremaneira. Cícero propunha a união entre res e verba e Richer anunciou, em seu prólogo, que havia aperfeiçoado a obra de Flodoard a partir do uso de dois utensílios oferecidos pela retórica: o uso das palavras corretas (verba) e o acréscimo de conteúdo (res) (RICHERI, 1845, Prologus, p. 4).

Richer foi o primeiro autor de textos históricos de toda a Idade Média a reconhecer a plausibilidade como elemento determinante na confecção de sua obra. Isso representou um corte nevrálgico nos padrões seguidos pelos intelectuais medievais que se dedicaram à elaboração de narrativas históricas. Mesmo que o procedimento de incorporar argumentos plausíveis fosse conhecido e utilizado por alguns eruditos, quem lançava mão desse recurso jamais admitia tê-lo feito (LAKE, 2009, p. 225).

Muitos dos especialistas que se debruçaram sobre a obra de Richer se mostraram "indignados com suas aproximações cronológicas, com sua falta de escrúpulo crítico, com seus discursos inteiramente inventados" (SOT, 1988, p. 725). ${ }^{28}$ Não pretendemos aqui tirar a razão de quem pensa assim. Consideramos, contudo, que essa indignação se mostrou legítima apenas "quando se tratava de reconstituir a historia factual do período" (SOT, 1988, p. 725). ${ }^{29}$ O que pode parecer distorção e fraude para os historiadores 
atuais, para os historiógrafos medievais - e aqui enfatizamos aqueles que se filiavam à tradição ciceroniana - era parte constitutiva de seu trabalho intelectual. Para ler as narrativas escritas na Idade Média que pretendiam se debruçar sobre temáticas históricas é preciso ter como ponto de partida que "o historiador na Idade Média tinha padrões de evidência diferentes dos que têm um historiador hoje" (GRANSDEN, 1992, p. 128). ${ }^{30}$ A análise dessas obras não pode ser feita sem a necessária contextualização dos paradigmas utilizados em cada época para a construção da narrativa histórica. $\mathrm{O}$ historiador tem como tarefa precípua entender cada período através da análise dos seus traços culturais, políticos, econômicos, intelectuais, sociais.

A utilização da plausibilidade como recurso intelectual a serviço da produção de obras históricas pode revelar muito sobre os valores e costumes de uma sociedade. Ela não era um mecanismo erudito desonesto utilizado para ludibriar o público leitor ou ouvinte e tirar vantagens das propostas elencadas pelos autores que se utilizam de suas estratégias discursivas. "Era um padrão separado e distinto aplicado para a prática da exaedificatio retórica." (LAKE, 2009, p. 234). ${ }^{31}$ No caso de Richer, quando ele assevera escrever lastreado pela plausibilidade "ele faz uma afirmação positiva sobre a superestrutura narrativa do seu trabalho" (LAKE, 2009, p. 234) ${ }^{32}$, mesmo que não seja possível encontrar 'a verdade' nas histórias que suas páginas contam.

\section{Fontes}

CICERONIS, M. Tulli. De oratore. Libri tres, volumen I. Prussorum Regimontii: Sumptus Fecerunt Fratres Borntraeger, 1840.

FLODOARD. Histoire de l'Église de Reims,. Reims: P. Regnier, Imprimeur de 1' Académie, deux tomes, 1854.

FLODOARD. Les Annales de Flodoard. Paris: Picard, 1905.

RICHER. Histoire de France. Paris: Librairie Ancienne Honoré Champion, 1930.

RICHERI. Historiarum Libri Quatuor. Paris: Chez Jules Renouard, 1845.

\section{Referências Bibliográficas}

AILES, Marianne. Early French chronicle: history or literature? In: Journal of Medieval History, vol. 26, 2000, n³, p. 301-312.

BASSI, Rafael. A escrita da História e o rei. São Leopoldo: Oikos, 2014.

BRAUDEL, Fernand. Escritos sobre a História. São Paulo: Perspectiva, 1992.

DELIYANNIS, Deborah Mauskopf (ed.) Historiography in the Middle Ages. Leiden, Boston: Brill, 2003.

GEARY, Patrick. Phantoms of remeberence: memory and oblivion at the end of first millennium. New Jersey: Princeton University Press, 1994. 
GLENN, Jason. Politics and History in the Tenth Century: the work and world of Richer of Reims. Cambridge: Cambridge University Press, 2004.

GRANSDEN, Antonia. Legends, tradition and History in medieval England. London and Rio Grande: The Hambledon Press, 1992.

GUENÉE, Bernard. Histoire et Culture Historique dans l'Occident Médiéval. Paris: Aubier, 1980.

. Les premiers pas de l'histoire de l'historiographie en Occident au XIIe siècle. In: Comptes-rendus de séances de l'Académie des Inscriptions et Belle-Lettres, 127e année, $n^{\circ} 1,1983$, p. 136-152.

Histoires, annales, chroniques. Essai sur les genres historiques au Moyen Âge. In: Annales. Économies, Sociétés, Civilisations. 28e année, nº4, 1973, 997-1016.

LAKE, Justin. Truth, plausibility, and the virtues of narrative at the millennium. In: Journal of Medieval History, vol. 35, 2009, p. 221-238.

LAPINA, E. 'Nec signis nec testis credibus...': the problem of eyewithnesses in the chronicles of the first crusade. In: Viator, 38/1 (2007), p.117-139.

MENANT, François; MARTIN, Hervé; MERDRIGNAC, Bernard; CHAUVIN, Monique. Les capétiens: histoire et dictionnaire, 987-1328. Paris: Robert Laffont, 1999.

ORCÁStegui, C.; SARASA, E. (Orgs.). La historia en la Edad Media. Historiografia e historiadores en Europa Occidental: siglos V-XIII. Madrid: Ediciones Cátedra, 1991.

PERNOT, Laurent. La rhétorique dans l'Antiquité. Paris: Librairie Générale Française, 2000.

RUST, Leandro Duarte A Reforma Papal (1050-1150): trajetórias e críticas de uma história. Cuiabá: Ed. UFMT, 2013.

SASSIER, Yves. Hugues Capet. Paris: Fayard, 1987.

SEGUY, M.; LUCKEN, C. L’invention de l'histoire. In: Médiévales, n³8, 2000.

SOT, Michel. Un historien et son Église au Xe siècle: Flodoard de Reims. Paris: Fayard, 1993.

Hérédité royale et pouvoir sacré avant 987. In: Annales. Économies, Sociétés, Civilisations. 43e année, $n^{\circ} 3,1988$, p. 705-733.

SPIEGEL, Gabrielle. The past as text. Baltimore/London: Johns Hopkins University Press, 1997.

STROH, Wilfried. La puissance du discours. Une petite histoire de la rhétorique dans la Grèce antique et à Rome. Paris: Les Belles Lettres, 2010.

TEIXEIRA, Igor Salomão e BASSI, Rafael (orgs.). A escrita da história na Idade Média. São Leopoldo: Oikos, 2015.

VAN DER BLOM, Henriette. Cicero's Role Models. The Political Strategy of a Newcomer. New York: Oxford University Press, 2010.

VERGER, Jacques. Homens e saber na Idade Média. Bauru: Edusc, 1999. 


\title{
WICKHAM, Chris. O legado de Roma. Iluminando a idade das trevas, 400-1000. Campinas: Editora Unicamp, 2019.
}

\begin{abstract}
${ }^{1}$ Professor de História Antiga e Medieval da Universidade Federal do Oeste da Bahia. Doutorando em História pelo PPGH-UFBA.

${ }^{2}$ Leandro Rust - sobretudo em A Reforma Papal - critica a existência de uma Reforma Gregoriana ocorrida no seio da Igreja Romana que tivesse sido imposta à cristandade. Rust assevera que os argumentos que consolidaram a ideia de reforma - que teve como grande artífice o historiador católico Augustin Fliche (1884-1951) - precisam ser revistos a partir de uma reconsideração da bibliografia associada a uma revisão dos documentos. Fliche propôs que o fortalecimento do poder papal principalmente a partir de 1049, pontificado de Leao IX, mas que teve como principal representante Gregório VII (1073-1085) - foi uma resposta ao cenário de 'caos feudal' que teria se seguido à desagregação de uma autoridade laica que pudesse se impor em um contexto marcado pela fragmentação política. As transformações que se seguiram contemplaram, segundo o historiador francês, uma ampla gama de ações que se contrapunham ao nicolaísmo, à simonia, à corrupção relacionada aos valores cristãos, a rapina orquestrada pelas aristocracias. Amparado pela produção historiográfica e pela revisão de algumas fontes que ajudaram a consolidar a ideia da existência de uma "Revolução Papal" entre os séculos XI e XIII, Rust defende a ideia de que as reformas eram uma demanda da sociedade e não podem ser vistas como medidas tomadas pelo alto clero e impostas unilateral e inescapavelmente. RUST, Leandro Duarte A Reforma Papal (1050-1150): trajetórias e críticas de uma história. Cuiabá: Ed.
\end{abstract} UFMT, 2013.

${ }^{3}$ As traduções das notas que aparecem em inglês, francês e latim são de nossa inteira responsabilidade. "medieval social life was governed by costum, that is, historical precedent, so much that even innovations in social and legal practices were given the force of costum."

3 "Gallorum congressibus in volumine regerendis, imperii tui, pater sanctissime Gerberte, auctoritas seminarium dedit. Quam, quia summan utilitatem affert, et rerum materia sese multiplex praebet, eo animi nisu complector, qua jubentis mira benivolentia pertrahor."

${ }^{4}$ FLODOARD. Les Annales de Flodoard. Collection des textes pour servir à l'étude et à l'enseignement de l'histoire 39. Paris: Picard, 1905. FLODOARD. Histoire de l'Église de Reims. Reims: P. Regnier, Imprimeur de l' Académie, deux tomes, 1854.

6 "his work attests to at least a basic grasp of the quadrivium [...] but, given his historical production and displays of rhetorical skill therein, he probably devotes more time to the trivium."

7 "not merely legislative purposes, but also a historical records of Frankish past."

8 "Plus une source est ancienne, se disait'on, et mieux elle doit appréhender un fait ancien. Et on peut accorder la plus grande confiance aux textes contemporains des faits qu'ils rapportent."

9 "with decidedly casual relationship to the truth."

10 "the medieval 'historians' concept of 'truth' differed from ours."

11 "simplement, sa critique historique reposait sur des principes qui ne sont plus les nôtres."

12 '“'Everybody knows that the first law of history is not daring to say anything false.' (Nam quis nescit, primam esse historiae legem, ne quid falsi dicere audeat?)" [...] "a moral-didactic view of history, which necessitates a certain level of historical plausibility."

13 "all references to historical exempla must be truthful and comprehensive in all aspects."

14 "displayed history as a flexible matter in which interpretations could vary in order to make specific points, as long as the representation was credible and convincing."

15 "[...] qualis oratoris et quanti hominis in dicendo putas esse historiam sccribere?"

16 "[...] Si, ut Graeci scripserunt, summi, [...] si, ut nostri, nihil opus est oratore; satis est non esse mendacem."

17 "Erat enim historia nihil aliud nisi annaluim confectio."

18 "Hanc similitudinem scribendi multi secuti sunt, qui sine ullis ornamentis monumenta solum tempore hominum locum gestarumque rerum reliquerunt."

19 "actively engaged in producing that tradition through a complex process of transmission, suppression and re-creation."

20 "Omnium ergo Galliarum populi innata audatia plurimum efferuntur, calumniarum impatientes. Si incitantur, cedibus exultant, efferatique inclementius adoriuntur. Semel persuasum ac rationibus 
approbatum, vix reffelere consuerunt. Unde et Hieronimus: 'Sola, inquit, Gallia monstra non habuit, sed viris prudentibus et eloquentissimis sempre claruit."”

21 "[...] Heribertus comes obiit, quem sepelierunt apud Sanctum Quintinum filii sui; [...]."

22 "XXXVII - Interitus Heriberti. His ita sese habentibus, cum Heribertus quaeque pernitiosa pertractaret, ac de quorundam calamitate multa disponeret, cum inter suos in veste praeciosa vesteret, atque apud illos extensa manu concionaretur, majore apoplexia ob superfluitatem humorum captus, in ipsa rerum ordinatione, constrictis manibus nervisque contractis, ore etiam in aurem distorto, cum multo horrore et horripilatione coram suis inconsultus exspiravit. Susceptusque a suis, apud Sanctum Quintinum sepultus est. Quo sepulto, ejus filii mox regem adeuntes, ab eo benigne excepti sunt. Patris injuriarum nihil sibi reducens. [...]"

23 "reveal themselves as deeply committed to the written word for communication, administration and record."

24 "made known measures of legislation, and administration, exhortation, statements of policy and moral fervour."

25 "“...] Deroldus, Ambianensium praesul, vita decessit."

${ }^{26}$ Para o entendimento das Histórias de Richer, na perspectiva adotada por essa pesquisa, é preciso que fique estabelecido o diálogo entre plausível e verossímil balizado pela retórica ciceroniana. Cícero definiu a História como assunto dotado de uma flexibilidade capaz de gerar interpretações variadas que estariam na origem de versões diferentes dos eventos narrados. Essas narrativas seriam convincentes desde que fossem verossímeis, capazes de convencer quem as ouvisse ou lesse. Para atingir essa verossimilhança, o orador que cuidasse de contar ou escrever a História poderia - mais do que isso, deveria - lançar mão de argumentos ou de ficções plausíveis. Quanto mais convincentes as construções plausíveis fossem para a audiência, mais bem sucedidas seriam consideradas, exatamente por terem se mostrado mais verossímeis. Destarte, a plausibilidade seria um caminho para se atingir a verossimilhança.

27 "LIX - Qualiter Deroldus a quodam medico deceptus sit eumque deceperit. Quo tempore Ambianensium episcopus, Deroldus, ab haec vita decessit, vir spectabilis ac palatines, et quondam et regi admodum dilectus, in arte medicinae peritissimus. De quo etiam fetur quod, cum adhuc in palatio regi serviret, a quodam Salernitano medico deceptus sit, eumque deceperit. Etenim cum uterque in arte medicinae optime posset, et iste rege potior, Salernitanus vero reginae peritior videretur, comment regis repertum est quis eorum rerum naturas magis dinosceret. Jussit etenim coram se illos consedere convivas, causam rei penitus dissimulans, ac sepe eis questions proponens. Quisque ut potera proposita solvebat. Deroldus quidem, utpote litterarum artibus eruditus, probabiliter objecta diffiniebat.. Salernitanus vero licet nulla litterarum scientia praeditus, tamen ex ingenio naturae, multam in rebus experientiam habebat. Regio itaque jussu cotidie consident, ac mensa regia continue una potiuntur. Et die quadam de dinamidiarum differentiis disputatum est; tractatumque uberius quid efficiat farmaceutica, quid vero cirurgica, quid etiam butanica. At Salernitanus, peregrina nomina non advertens, ab eorum interpretatione erubescens quievit. Invidet ergo plurimum, ac in ejus mortem venenum parare meditatur; multam dolose benivolentiam simulans. Parato vero maleficio, cum una in prandio residerent, Salernitanus ungue inpudici toxicato, liquorem piperis quo cibum partier intinguebant, loetaliter inficit. Quo Deroldus incaute sumpto, mox seprente veneno, deficere coepit. Eductusque a suis, teriaca vim veneni repellit. Et triduo expleto coram rediens, Salernitano consuescebat. Interrogatus vero quid ei accidisset, fleumatis frigdore se levitus tactum respondit; quicquam fraudis se perpendisse dissimulans. Unde et hostem incautum efficit. Convivae itaque redditi, Deroldus toxicum inter auricularem ac salutarem occultatum, ejus cibo sumendo respersit. Quod mox venis serpens, vitae calorem fugabat. Vexatusque a suis eductus est. Qui veneno expellendo operam dans, nihil curae agebat. Deroldum itaque magnificans, summumque eum in medicina praedicans, ejus curam vehementissime petebat. Qui regis jussu flexus, antidotis datis a toxico per industriam non ex toto purgavit. Nam sumpta teriaca, vis veneni in pedem sinistrum penitus dilapsa est; in tantum ut apud domesticos eo familiariter agente, venenum, ut fertur, in modum ciceris a pede per venam surgens, ab antidoto obviante in pedem repelleretur. Quibus diutissime sic repugnantibus, pes in cutis superficie foratur. Factoque morbo, post a cirurgis miserabiliter absciditur."

28 "indignés de ses approximations chronologiques, de son manque de scrupule critique, de ses discours inventés de toute pièce."

29 "quand il s'agissait de reconstituer l'histoire événementielle de la période."

30 "the historian in the Middle Ages had different standards of evidence from those of an historian today."

31 "It was a separate and distinct standard applied to the practice of rethorical exaedificatio."

32 "he is making a positive claim about the narrative superstructure of his work." 